\title{
SARCOIDE EQUINO: REVISÃO DE LITERATURA
}

\author{
Mariana Pinheiro \\ Muriel Magda Lustosa Pimentel ${ }^{2}$ \\ Paula Bittencourt Vago ${ }^{1}$ \\ Raimundo Alves Barrêto Junior ${ }^{3}$ \\ Regina Valéria da Cunha Dias ${ }^{3}$
}

PINHEIRO, M.; PIMENTEL, M. M. L.; VAGO, P. B.; BARRÊTO JUNIOR, R. A.; DIAS, R. V. da C. Sarcóide equino: revisão de literatura. Arq. Ciênc. Vet. Zool. UNIPAR, Umuarama, v. 18, n. 2, p. 103-107, abr./jun. 2015.

\begin{abstract}
RESUMO: Entre todas as especialidades veterinárias, a dermatologia e a oncologia vêm se destacado. Nos equinos, além de causar problemas econômicos, as lesões de pele são um importante problema estético. A pele é o local mais comum de neoplasmas em equinos, perfazendo aproximadamente $50 \%$ de todos os tumores. Entre os principais destacam-se sarcoide, carcinoma de células escamosas, papiloma e melanoma. O sarcoide é a neoplasia cutânea mais frequente em equinos, e corresponde a um terço de todos os tumores descritos nesta espécie.Clinicamente são classificados em seis tipos: verrucoso, superficial, nodular, fibroblástico, maligno ou misto. O diagnóstico é dado mediante biopsia da pele e estudo histopatológico. A ligadura, remoção cirúrgica, criocirurgia, cirurgia a laser, eletroquimioterapia com uso de cisplatina intralesional, uso de $\mathrm{BCG}$, radioterapia e uso tópico de aciclovir são opções de técnicas de tratamentos de tumores. O protocolo de tratamento deve ser escolhido com critérios pelo veterinário, já que para cada protocolo existem indicações diferentes e eficácias variáveis, que dependem do tipo de tumor, tamanho e sua localização. Esta revisão visa a descrever técnicas de tratamentos disponíveis na literatura para o sarcoide equino, além de esclarecer a etiologia, suas características histológicas e aspectos clínicos para melhor abordagem no diagnóstico desta neoplasia. De acordo com o descrito na literatura, o sarcoide equino é a neoplasia cutânea mais frequente na rotina clínica, o que determinou a escolha desta revisão, possibilitando, assim, um maior conhecimento acerca dessa afecção e dos tratamentos disponíveis no mercado.
\end{abstract}

PALAVRAS-CHAVE: Neoplasia. Equino. Tratamento. Diagnóstico.

\section{EQUINE SARCOID: LITERATURE REVIEW}

\begin{abstract}
Among all veterinary specialties, dermatology and oncology have stood out lately. In horses, besides causing economic problems, skin lesions are a major aesthetic issue. The skin is the most common place for neoplasms in horses, making up about $50 \%$ of all tumors. Among the main ones, there are sarcoid, squamous cell carcinoma, papilloma and melanoma. Sarcoid is the most common skin neoplasia in horses, and corresponds to a third of all tumors reported in this species. They are clinically classified into six types: verrucous, superficial, nodular, fibroblastic, malignant or mixed. Diagnosis is made through skin biopsy and histopathology. Bandage, surgical removal, cryosurgery, laser surgery, electrochemotherapy with intralesional cisplatin, use of BCG, radiotherapy and topical acyclovir are techniques for tumor treatments. The treatment protocol should be carefully chosen by the veterinarian, since for each protocol there are different indications and efficacy variables, depending on the tumor type, size and location. This review aims to describe techniques available in literature for the treatment of equine sarcoid as well as the etiology, clinical features and histologic aspects for the best approach in the diagnosis of this neoplasm. According to literature, equine sarcoid is the most frequent skin cancer in clinical routine, which has determined the choice of this review, enabling a greater knowledge about this disease and the treatments available.
\end{abstract}

KEYWORDS: Neoplasia. Equine. Treatment. Diagnosis.

\section{SARCOIDE EQUINO: REVISIÓN DE LITERATURA}

RESUMEN: Entre todas las especialidades veterinarias, la dermatología y oncología se han destacado. En los equinos, además de causar problemas económicos, lesiones de la piel son un problema estético importante. La piel es el sitio más común de las neoplasias en equinos, que comprenden aproximadamente el 50\% de todos los tumores. Entre los principales se destacan sarcoide, carcinoma de células escamosas, papiloma y melanoma. El sarcoide es la neoplasia más frecuente en equinos, y corresponde a un tercio de todos los tumores reportados en esta especie. Clínicamente se clasifican en seis tipos: verrugosas, superficiales, nodulares, fibroblastos, maligno o mezclado. El diagnóstico es dado a través de biopsia de la piel y estudio histopatológico. El vendaje, la extirpación quirúrgica, criocirugía, la cirugía a láser, electro quimioterapia intralesional con cisplatino, uso de BCG, radioterapia y aciclovir tópico son opciones de técnicas para tratamiento de tumores. El protocolo de tratamiento debe ser elegido con criterio por el veterinario, ya que para cada protocolo hay diferentes indicaciones y variable de eficacia, dependiendo del tipo de tumor, tamaño y ubicación. Esta revisión tiene como objetivo describir las técnicas de tratamientos disponibles en la literatura para sarcoide equino, además de aclarar la etiología, sus características histológicas y aspectos clínicos para mejor enfoque en el diagnóstico de la neoplasia. De acuerdo con el descrito en la literatura, el sarcoide equino es la neoplasia cutánea más frecuente en la rutina clínica, lo que ha determinado la elección de esta revisión, permi-

DOI: https://doi.org/10.25110/arqvet.v18i2.2015.5380

${ }^{1}$ Médica Veterinária autónoma. E-mail para correspondência: marykiedis@hotmail.com

${ }^{2}$ Especialista em Clínica Cirúrgica e Reprodução de Equinos - Mossoró-RN, Brasil

${ }^{3}$ Professor (a) Dr (a). do Departamento de Ciências Animais - UFERSA, Mossoró-RN, Brasil 
tiendo mayor conocimiento acerca de esa enfermedad y los tratamientos disponibles en el mercado.

PALABRAS CLAVE: Neoplasia. Equino. Tratamiento. Diagnóstico.

\section{Introdução}

É a neoplasia cutânea mais frequente entre os equinos e o único tumor cutâneo encontrado em asininos, muares e zebras (SOUZA et al., 2011; BROMERSCHENKEL et al., 2013). Não possui predileção por raças, entretanto, há maior susceptibilidade nos animais Appaloosa, Puro Sangue Árabe, Quarto de Milha, Paint Horse, Puro Sangue Inglês e Crioulo (CREMASCO et al., 2010). Acomete animais com idade entre um e seis anos (KNOTTENBELT et al., 2008), independente de sexo e características de pelagem (CREMASCO et al., 2010).

São lesões que não sofrem influência sazonal e sua ocorrência tem sido relatada em várias regiões do mundo (CREMASCO et al., 2010). Diversos estudos têm sido realizados no Brasil na tentativa de determinar a prevalência de sarcoide equino. Em estudo retrospectivo, com revisão de artigos do Laboratório de Patologia Animal (LPA) da Universidade Federal de Campina Grande (UFCG), Campus de Patos - Paraíba, durante os anos de 1983 a 2010, relatou-se que $55 \%$ dos equídeos examinados apresentaram a neoplasia (CARVALHO, 2012). No Rio Grande do Sul, no Laboratório de Patologia Veterinária (LPV) da Universidade Federal de Santa Maria (UFSM), nos anos de 1999 a 2009, foi realizada revisão de protocolos de biopsia de pele de equinos com taxa de prevalência de 57,4\% de animais acometidos com sarcoide equino (CESCON et al., 2011; SOUZA et al., 2011).

Esta revisão visa descrever técnicas de tratamentos disponíveis na literatura para o sarcoide equino, além de esclarecer a etiologia, suas características histológicas e aspectos clínicos para melhor abordagem no diagnóstico desta neoplasia.

\section{Desenvolvimento}

O sarcoide equino é uma neoplasia comum, fibroblástica e localmente agressiva dos cavalos, frequentemente ocorre em áreas sujeitas a traumas, podendo existir histórico de ferimentos no local entre três e seis meses antes do surgimento do sarcoide. As lesões são com maior frequência múltiplas e de ocorrência muito variável, podendo surgir repentinamente e perdurar por longos períodos, como também podem regredir e desaparecer espontaneamente. $\mathrm{O}$ aparecimento deste tipo de lesão não sofre influência climática, sua ocorrência tem sido relatada em várias regiões do mundo. Este tumor foi descrito pela primeira vez em 1936 na África do Sul por Jackson e foi descrito como uma condição fibroblástica semelhante a tumor da pele equina com componente epitelial variável e grande propensão à recorrência (GOMIE$\mathrm{RO}, 2014)$

\section{Etiologia}

Embora suas características clínico-patológicas estejam estabelecidas, a etiologia do sarcoide equino ainda não está esclarecida (CREMASCO et al., 2010), entretanto, sua caraterística multifatorial já está definida (BERGVALL, 2013).
A associação de agentes infecciosos do Papilomavírus Bovino (BPV) e a susceptibilidade genética do indivíduo são fatores importantes para o desenvolvimento do sarcoide equino (ÁLVAREZ; VILORIA; AYOLA, 2013; BERGVALL, 2013). Apesar de ser espécie-específica, o BPV-1 e menos comumente o BPV-2, são agentes causadores de tumores de pele em equinos, muares, asininos e zebras (YUAN et al., 2008; ÁLVAREZ; VILORIA; AYOLA, 2013), sendo identificados na maioria das lesões de sarcoide equino (CREMASCO et al., 2010; BERGVALL, 2013). Recentemente foi confirmado no Brasil a ocorrência de sarcoide equino associado à infecção pelo BPV-4 (ANJOS et al., 2010), que possui grande similaridade com o BPV-2 isolado em outros casos da neoplasia no país (CARVALHO, 2012).

O DNA viral tem sido encontrado em pele normal de equinos, o que sugere a existência de uma fase de latência do processo, assim como explicaria a alta taxa de recorrência após a excisão cirúrgica (CREMASCO et al., 2010).

A produção da proteína transformante (E5) dos BPVs tipo 1 e 2 no sarcoide equino parece contribuir para a persistência do vírus e para a patogênese da doença por reduzir a expressão do complexo principal de histocompatibilidade classe I (MHC-I). Podendo ser o mecanismo de evasão utilizado pelo BPV e que tem sido relatado como responsável pela progressão maligna associada a neoplasias com papilomavírus. Além disso, existe uma forte associação entre o risco de desenvolvimento do sarcoide com determinados alelos do MHC classe II sugerindo a predisposição genética ao desencadeamento deste tipo de tumor (CREMASCO et al., 2010).

Já é demonstrado que o genoma do BPV-1 pode transformar fibroblastos equinos, fazendo com que se proliferem mais rápido, tenham longa sobrevivência e crescimento independente de substrato, mostrando-se mais pronunciado com as expressões dos genes E5, E6 e E7. As oncoproteínas E6 e E7 são ativadas via proteína 1, e a E5 é regulada pela metaloproteinase de matriz tipo 1, contribuindo com a capacidade de invasão dos fibroblastos (BERGVALL, 2013).

Estudos têm sido realizados na tentativa de elucidar a participação das metaloproteinases de matriz (MMP) na etiologia do sarcoide equino. Segundo Yuan et al. (2010), as células de sarcoide são invasivas, sendo essa invasão dependente da produção de MMPs, que são reguladas pelo BPV-1. Os autores relatam que a super expressão ou o aumento das atividades das MMPs, é provavelmente a causa da invasão de células tumorais para os tecidos circundantes, o que pode ser uma das razões da elevada recorrência e a consequente dificuldade de tratamento de sarcoide equino.

Ainda é desconhecido se a infecção por BPV em equinos pode ocorrer de um equino para outro, se pode ser transmitida de bovinos para equinos e como o BPV pode causar infecção em hospedeiros não naturais. Contudo, Álvarez, Viloria eAyola (2013) relatam que pode haver infecção por contato direto com bovinos e equinos contaminados. Citam, ainda, que pode ocorrer envolvimento de mosquitos e moscas como vetores da enfermidade, visto que as lesões tumorais podem surgir em áreas preferenciais de picadas dos mesmos. 


\section{Características histológicas}

É uma neoplasia de tecido fibroso, com origem fibroblástica, não metastático, com envolvimento frequente da epiderme (CREMASCO et al., 2010), a qual está hiperplásica ou ainda com hiperqueratose (QUINN, 2003).

Tem sido descrito como um tumor frequentemente bifásico, com componentes dérmico e epidérmico (BRUM; SOUZA; BARROS, 2010). Caracteriza-se por tumores mesenquimais (QUINN, 2003), com proliferação dérmica densa de fibroblastos, formando ninhos e feixes entrelaçados e assumindo várias direções (BRUM; SOUZA; BARROS, 2010). As células neoplásicas são fusiformes ou estreladas, com núcleo alongado, que mostram hipercromasia e atipia (CREMASCO et al., 2010). As taxas de mitose são baixas e há pouca vascularização (BRUM; SOUZA; BARROS, 2010).

\section{Aspectos Clínicos}

As lesões mais comuns no sarcoide equino são vistas em pele fina e com áreas de pouco pêlo como a face medial dos membros, codilhos, virilhas, face, pálpebras, orelhas (QUINN, 2003), comissura labial, região cervical, abdominal ventral e paragenital (CREMASCO et al., 2010). Esses locais, muitas vezes, estão expostos a traumas ou danos na pele (NASIR; CAMPO, 2008).

O sarcoide equino apresenta seis formas distintas, visivelmente diferentes e histologicamente reconhecíveis, classificadas em oculto, verrucoso, nodular, fibroblástico, misto e maligno (KNOTTENBELT et al., 2008; CREMASCO et al., 2010; ÁLVAREZ; VILORIA; AYOLA, 2013; BERGVALL, 2013; BROMERSCHENKEL et al., 2013).

O tipo oculto é caracterizado por áreas focais e circulares com alopecia, descamação, espessamento da pele, hiperqueratose e hiperpigmentação. Usualmente contém um ou mais nódulos cutâneos de 2-5 mm de diâmetro ou áreas com uma pequena mudança na pele. Apresenta predileção por locais como a pele ao redor da boca e olhos, pescoço, face, parte medial dos membros, codilho e virilhas (KNOTTENBELT et al., 2008; BERGVALL, 2013). Possui como diagnóstico diferencial foliculites infecciosas (bacterianas e dermatofitoses) e alopecia areata (BERGVALL, 2013).

O tipo verrucoso tem aparência de verruga com graus variáveis de descamação e dimensão, em áreas mais limitadas ou amplas do corpo. Apresenta-se como áreas de alopecia, com aspecto áspero, superfície levantada e irregular, afetando áreas extensas e circundadas por pele mais espessa e pêlo mais fino (KNOTTENBELT et al., 2008; BERGVALL, 2013). Lesões individuais podem ser fixas ou penduculadas, dando a aparência de verruga, não crescem com rapidez e não são muito agressivas, até ocorrência de algum trauma (KNOTTENBELT et al., 2008). Pequenos nódulos podem aparecer em qualquer área do corpo, com predileção por cabeça, pescoço, codilho e virilha. Diferencia-se de papilomas (BRUM; SOUZA; BARROS, 2010; BERGVALL, 2013).

O sarcoide equino tipo nodular, caracteriza-se por lesões, facilmente reconhecíveis, firmes e bem definidas no tecido subcutâneo como nódulos esféricos (5-20 mm de diâmetro). A quantidade é variável podendo chegar a centenas (KNOTTENBELT et al., 2008) e é dividido em subtipo A e
B. O subtipo A apresenta-se como lesões únicas ou agregados lobulares de massas subcutâneas esféricas. Já o subtipo $\mathrm{B}$ é representado por nódulos múltiplos com envolvimento cutâneo não aderidos ao tecido subjacente (CREMASCO et al., 2010), com a pele mais fina sobre os nódulos maiores, os quais podem ulcerar tornando os tumores mais agressivos (KNOTTENBELT et al., 2008). São encontrados nas áreas palpebrais, virilhas e prepúcio (KNOTTENBELT et al., 2008; CREMASCO et al., 2010; BERGVALL,2013).

Os tumores tipo fibroblásticos possuem aparência fibrovascular, semelhante ao tecido de granulação, com massas ulceradas (CREMASCO et al., 2010; ÁLVAREZ; VILORIA; AYOLA, 2013; BERGVALL, 2013). Dividem-se em tipo 1 onde é pedunculado e estreito, e tipo 2 apresentando uma base ampla e invasiva (KNOTTENBELT et al., 2008; BERGVALL, 2013). Ambos são tumores fixos, pedunculados, extensos e, ulcerações e exsudatos são encontrados com frequência (KNOTTENBELT et al., 2008). Tem predileção por áreas da região periocular, virilhas, membros e coroa dos cascos (KNOTTENBELT et al., 2008; CREMASCO et al., 2010; BERGVALL, 2013). Possui uma predisposição a evoluir para uma forma mais severa naqueles locais que apresentam cicatrização insatisfatória devido a procedimento cirúrgico, além de áreas sujeitas a traumas repetitivos (KNOTTENBELT et al., 2008). Assemelham-se a tecido de granulação, pitiose, habronemose e carcinoma de células escamosas (BRUM; SOUZA; BARROS, 2010; BERGVALL, 2013)

O tipo misto é relativamente comum e apresenta lesões que possuem características pertencentes a dois ou mais tipos dos tumores descritos anteriormente (CREMASCO et al., 2010). Knottenbelt et al. (2008) relatam este tipo como sendo uma progressão ou transição de fase entre o tipo verrucoso e oculto e, dos tipos nodulares e fibroblásticos.

A forma maligna é agressiva e localmente invasiva com infiltração dos vasos linfáticos, resultando em múltiplos cordões de massas tumorais que se estendem amplamente na pele e tecido subcutâneo adjacente (CREMASCO et al., 2010; BERGVALL, 2013). Os locais de eleição são as áreas da mandíbula, face (principalmente na região periocular), codilho, face medial da coxa. Não há tratamento para este tipo maligno (KNOTTENBELT et al., 2008).

Os tipos oculto e verrucoso podem permanecer estáticos se não forem manipulados ou traumatizados. Embora com menor frequência, a forma nodular pode permanecer inerte. Quaisquer dos tipos de sarcoide equino podem evoluir para os tipos fibroblástico ou maligno caso sejam lesionados (BERGVALL, 2013). As formas clínicas podem associar-se em um mesmo animal, com localizações diferentes não havendo risco de metástase (ÁLVAREZ; VILORIA; AYOLA, 2013).

Apesar das condições do sarcoide equino não serem letais, o tamanho e a distribuição dos tumores podem comprometer severamente a sanidade e a utilidade dos equinos, o que pode levar a decisão da eutanásia (BERGVALL, 2013).

\section{Diagnóstico}

O diagnóstico de sarcoide equino é baseado no histórico, apresentação clínica e exame histopatológico (KNOTTENBELT et al., 2005; BROMERSCHENKEL et al., 2013). 
A biopsia é realizada tanto para diferenciar o sarcoide equino de outras enfermidades como também para determinar a escolha do tratamento. Contudo, é necessário cautela na escolha da sua realização, já que o simples trauma da técnica pode levar a proliferação e evolução do tumor (KNOTTENBELT et al., 2008).

Nos últimos anos tem sido utilizada a biologia molecular como opção de diagnóstico por meio da técnica de reação em cadeia de polimerase (PCR) que demonstra a presença de DNA BVP-1 ou BVP-2 (BERGVALL, 2013).

\section{Tratamento}

O tratamento desta neoplasia tem sido um desafio devido às diversas apresentações clínicas e as recorrências frequentes. Assim, deve-se fazer uma seleção cuidadosa para cada indivíduo e tipo de sarcoide, levando em consideração a localização, o número e tamanho dos tumores, histórico do caso, valor financeiro do animal e aprovação do proprietário para cumprir o esquema de tratamento (MARTENS et al., 2000).

Existe uma grande variedade de tratamentos disponíveis, porém nenhuma terapia tem demonstrado ser universalmente eficaz na eliminação dos tumores (CESCON, 2012). Entre as terapias incluem-se negligência benigna, ligadura, remoção cirúrgica completa, crioterapia, hipertermia por radiofrequência, injeção intralesional com cisplatina, uso de 5- fluorouracil, laser com dióxido de carbono, radioterapia, administração de AW4-LUDES, imunomodulação com BCG, imiquimode, vacinas autólogas e aciclovir (KNOTTENBELT et al., 2008; STADLER et al., 2011; CESCON, 2012; BERGVALL, 2013; BROMERSCHENKEL et al., 2013).

A excisão cirúrgica é recomendada para remoção completa do tumor (CESCON, 2012), podendo apresentar recidiva no período de até seis meses após o tratamento (BRUM, 2010). Assim, para minimizar essa característica, deve ser feita cirurgia com margem de segurança de 0,5 a 1 $\mathrm{cm}$ de diâmetro, visto que é relatada a presença de DNA de BPV nas margens das lesões (CESCON, 2012; BERGVALL, 2013). É indicado nos casos de apresentação verrucosa, nodular e fibroblástica, principalmente quando forem pedunculados (SANTOS et al., 2011).

O tratamento cirúrgico também é utilizado com finalidade de aumentar a eficácia em casos mais graves quando se utiliza a associação de cirurgia e outras terapias, tais como crioterapia, compostos citotóxicos, injeções com cisplatina e hipertermia por radiofrequência (KNOTTENBELT et al., 2008; MARAIS et al., 2011; CESCON, 2012; BERGVALL, 2013).

A crioterapia é comumente utilizada e demonstra sucesso nos resultados. É realizada com nitrogênio líquido $\left(-185^{\circ} \mathrm{C}\right)$ ou óxido nitroso $\left(-80^{\circ} \mathrm{C}\right)$ e pode ser executada isoladamente ou depois de redução cirúrgica do tumor (CESCON, 2012; BROMERSCHENKEL et al., 2013). Pode ocorrer despigmentação da pele e pêlo, além de alopecia após o tratamento (KNOTTENBELT et al., 2008; CESCON, 2012), permanecendo durante 6 meses ou mais (GILGER, 2005).

Os princípios de crioterapia para garantir congelamento adequado incluem um ciclo de congelamento - descongelamento duplo ou triplo na lesão, com congelamento rápido e descongelamento lento. Os tecidos devem ser congelados a menos $-25^{\circ} \mathrm{C}$ e uma margem de $0,5 \mathrm{~cm}$ deve ser permitida ao redor da periferia de cada tumor (GILGER, 2005; CESCON, 2012). É recomendada a utilização de criossondas para controlar a temperatura tecidual, já que entre os congelamentos a pele deve descongelar completamente, antes da nova aplicação (BROMERSCHENKEL et al., 2013). Tratamentos repetidos podem ser necessários para lesões grandes ou recorrentes (GILGER, 2005).

\section{Conclusão}

De acordo com o descrito na literatura, o sarcoide equino é a neoplasia cutânea mais frequente na rotina clínica o que determinou a escolha desta revisão, possibilitando, assim, um maior conhecimento acerca dessa afecção e dos tratamentos disponíveis no mercado.

\section{Referências}

ÁlVAREZ, J. C.; VILORIA, M. V.; AYOLA, S. P. Sarcoide equino fibroblástico periocular enun burro (Eqqusasinus).

Revista CES Medicina Veterinária y Zootecnia, v. 8, n. 1, p. 98-107, 2013.

ANJOSI, B. L. et al. Sarcoide equino associado ao papilomavírus bovino BR-UEL-4. Ciência Rural, v. 40, n. 6, p. 1456-1459, 2010.

BERGVALL, K. E. Sarcoids. Veterinary Clinics of North America: Equine Practice, v. 29, n. 3, p. 657-671, 2013.

BROMERSCHENKEL, I.; FIGUEIRÓ, G. M. Tratamentos do sarcóide equino. Agropecuária Científica no SemiÁrido- ACSA, v. 9, n. 3, p. 07-10, 2013.

BRUM J. S.; SOUZA T. M.; BARROS, C. S. L. Aspectos epidemiológicos e distribuição anatômica das diferentes formas clínicas do sarcoide equino no Rio Grande do Sul: 40 casos. Pesquisa Veterinária Brasileira, v. 30, n. 10, p. $839-843,2010$

BRUM J. S. Sarcóide equino. 2010. 44 f. Dissertação (Mestrado em Medicina Veterinária) - Universidade Federal de Santa Maria, Santa Maria, 2010.

\section{CARVALHO, F. K. L. Neoplasias em ruminantes e} equídeos diagnosticadas no semiárido da Paraíba. 2012. 48 f. Dissertação (Mestrado em Medicina Veterinária) Universidade Federal de Campina Grande, Paraíba, 2012.

CESCON, G. T. et al. Estudo da prevalência de neoplasias em equinos no hospital de clínicas veterinárias da universidade federal do Rio Grande do Sul (2007-2011). In: CONGRESSO BRASILEIRO DE MEDICINA VETERINÁRIA., 2011, Florianópolis. Anais... Florianópolis, 2011.

\section{CESCON, G. T. Quimioterapia no tratamento de} neoplasias cutâneas em equinos. 2012. 50 f. Trabalho de Conclusão de Curso (Monografia) - Universidade Federal 
do Rio Grande do Sul, Porto Alegre, 2012.

CREMASCO, A. C. M.; SIQUEIRA, J. L. Sarcóide equino: aspectos clínicos, etiológicos e anatomopatológicos.

Veterinária e Zootecnia, v.17, n. 2, p. 191-199, 2010.

GILGER, B. C. Equine ophthalmology. Missouri: Elsevier Saunders, 2005. 475 p.

GOMIERO, R. L. S. Aspectos clínicos, anatomopatológicos e epidemiológicos do sarcóide equino - estudo de 30 casos. 2014. 33 f. Dissertação (Mestrado em Ciência Animal) - Universidade Federal do Paraná Campus Palotina, Curitiba, 2014.

KNOTTENBELT, D. C. A suggested clinical classification for the equine sarcóide. Clinical Techniques in Equine Practive, v. 4, n. 4, p. 278-295, 2005.

KNOTTENBELT, D. C. The equine sarcoid. In: INTERNATIONAL CONGRESS OF WORLD EQUINE VETERINARY ASSOCIATION, 10., 2008, Moscow. Proceedings... Moscow, fev. 2008.

MARAIS, H. J.; PAGE, P. C. Treatment of equine sarcoid in seven cape mountain zebra (equus zebra zebra). Journal of Wildlife Diseases, v. 47, n. 4, p. 917-924, 2011.

MARTENS, A. et al. Histopathological characteristics of five clinical types of equine sarcoid.Veterinary Science, v. 69 , n. 3, p. 295-300, 2000.

NASIR, L.; CAMPO, M. S. Bovine papillomaviruses: their role in the aetiology of cutaneous tumours of bovids and equids. Veterinary Dermatology, v. 19, n. 5, p. 243-254, 2008 .

QUINN, G. Skin tumours in the horse: clinical presentation and management. The VeterinaryRecord/In Practice, $n$. 25, p. 476-483, 2003.

SANTOS, D. E. Sarcóide fibroblástico periocular em equino - relato de caso. Revista Científica Eletrônica de Medicina Veterinária, ano 9, n.16, 2011.

SOUZA, T. M. et al. Prevalência dos tumores cutâneos de equinos diagnosticados no Laboratório de Patologia Veterinária da Universidade Federal de Santa Maria, Rio Grande do Sul. Pesquisa Veterinária Brasileira, v. 31, n. 5, p. 379-382, 2011.

STADLER, S. Successful treatment of equine sarcoids by topical aciclovir application. Veterinary Record, v. 168, n. $187,2011$.

YUAN, Z. Q. et al. Establishment and characterization of equine fibroblast cell lines transformed in vivo and in vitro by BPV-1: Model systems for equine sarcoids. Virology, v. 373, n. 2, p. 352-361, 2008.

YUAN, Z. Q. et al. Equine sarcoid fibroblasts over-express matrix metalloproteinases and are invasive. Virology, v. 396, n. 1, p. 143-151, 2010.

Recebido em: 27.05.2014

Aceito em: 27.08.2015 